\title{
Self-Reported Use of Personal Protective Equipment during the SARS-CoV-2 Pandemic in Emergency Medical Service Employees in Germany-A Survey
}

\author{
Theresa Berthold ${ }^{1,2^{*}}$, Jan-Thorsten Gräsner ${ }^{1,2,3,4 *}$, Janina Kosan ${ }^{1}$, Marcel Zill ${ }^{1,2}$, \\ Leonie Hannappel1,2, Birgitt Alpers ${ }^{1}$, Jan Wnent ${ }^{1,2,3,5}$ \\ ${ }^{1}$ Institute for Emergency Medicine, University Hospital Schleswig-Holstein, Kiel, Germany \\ ${ }^{2}$ COVID-19 Expert Working Group Intensive Care, Infectiology and Emergency Medicine (COVRIIN), Berlin, Germany \\ ${ }^{3}$ Department of Anesthesiology and Intensive Care Medicine, University Hospital Schleswig-Holstein, Kiel, Germany \\ ${ }^{4}$ Scientific Working Group Emergency Medicine of the German Society of Anesthesiology and Intensive Care Medicine (DGAI), \\ Nuremberg, Germany \\ ${ }^{5}$ School of Medicine, University of Namibia, Windhoek, Namibia \\ Email: "theresa.berthold@uksh.de
}

How to cite this paper: Berthold, T., Gräsner, J.-T., Kosan, J., Zill, M., Hannappel, L., Alpers, B. and Wnent, J. (2021) Self-Reported Use of Personal Protective Equipment during the SARS-CoV-2 Pandemic in Emergency Medical Service Employees in Germany-A Survey. Open Journal of Preventive Medicine, 11, 391-409. https://doi.org/10.4236/ojpm.2021.1111031

Received: October 9, 2021

Accepted: November 26, 2021

Published: November 29, 2021

Copyright $\odot 2021$ by author(s) and Scientific Research Publishing Inc. This work is licensed under the Creative Commons Attribution International License (CC BY 4.0).

http://creativecommons.org/licenses/by/4.0/ (c) (i) Open Access

\begin{abstract}
Background: Multicentric prospective cohort investigation survey conducted between $1^{\text {st }}$ of March and $1^{\text {st }}$ of April 2021on SARS-CoV-2 occupational risk for German Emergency Medical Services (EMS) personnel. Study Objectives: Primary: The objective is to take stock of the use and availability of Personal Protective Equipment (PPE) in German EMS, both at managerial and employee level, during the SARS-CoV-2 pandemic. Secondary: Generate additional data on individual perceptions of risk of infection and occurrence of infections at respective places of service. Methods: Multicentric prospective cohort investigation survey conducted online at two levels of German EMS personnel-EMS managers and EMS employees, both medical and paramedical-with questions adapted slightly to fit the respective study population. Results: A total of 34 responses were received in the managerial group; a total of 2389 responses were received in the group of employees. Self-reported PPE adherence of EMS employees for confirmed SARS-CoV-2 positive patients: use of gloves (99.8\%), FFP2 or FFP3 masks (99.8\%), gowns or coveralls (99.1\%), goggles $(89.7 \%)$, face shields $(24.0 \%)$, surgical masks $(0.0 \%)$. Self-reported PPE adherence of EMS employees for suspected SARS-CoV-2 positive patients: gloves (98.8\%), FFP2 or FFP3 masks (total: 99.4\%), gowns or
\end{abstract}

${ }^{\star}$ These authors contributed equally to this work.

"Corresponding author. 
coveralls (total: 95.9\%), goggles (85.6\%), face shields (19.2\%), surgical masks (0.2\%). Conclusions: Findings included an overall improved self-reported adherence to PPE compared to studies that were conducted before the pandemic. Self-reported general adherence to PPE recommendations when attending to confirmed SARS-CoV-2 positive patients was good, with the exception of goggles. Self-reported adherence to PPE recommendations dropped when attending to suspected SARS-CoV-2 positive patients.

\section{Keywords}

SARS-CoV-2, Personal Protective Equipment, Emergency Medical Services

\section{Introduction}

On $23^{\text {rd }}$ January, 2020, according to the World Health Organization (WHO), the first official SARS-CoV-2 cases were reported in Germany [1]. SARS-CoV-2 or severe acute respiratory syndrome coronavirus type 2 , a beta coronavirus, is the cause of the COVID-19 disease [2].

Over the course of the pandemic, an occupational risk for medical staff to contract COVID-19 was reported [3] [4] [5], as well as how transmission between medical personnel had been underestimated at the start of the pandemic [6]. On the $25^{\text {th }}$ of May 2021, the Centers for Disease Control and Prevention reported 491,816 healthcare workers in the United States to have been infected with COVID-19 [7]. No up-to-date figures are available regarding healthcare workers' infections worldwide, with estimates from the WHO dating back to 2020 [8]. There have been other efforts to collect data on healthcare workers' infections worldwide, however, these mostly focus on the year 2020 and do not include data from all countries [9] [10].

The main focus regarding COVID-19 occupational risks has been on hospital staff [5] [11] despite Emergency Medical Services (EMS) staff also having a high risk of exposure and infection with the virus [12] [13]. Some studies state that EMS staff have an increased risk of being infected with SARS-CoV-2 compared to the general population [14].

EMS personnel are often the first to attend to patients in situations that can be disordered and characterized by lack of information and time pressure [15] [16] [17]. These factors can negatively impact the adherence of EMS staff to PPE recommendations [18].

Availability and correct use of PPE is one important factor in protecting healthcare staff from infectious diseases, not just during the current pandemic. Particularly during the initial stages of an outbreak, when treatment options or vaccines are not available yet or only available in a limited number, PPE plays a vital role in safeguarding the health of medical and paramedical staff [19] [20].

Since current scientific data and reporting on SARS-CoV-2 occupational risk for German EMS workers is very limited, a survey was conducted in March 2021 
by the University Hospital Schleswig-Holstein, Institute for Emergency Medicine (IRuN) in Kiel. To our knowledge, this is the first study of this kind conducted in Germany.

The primary objective of the survey was to take stock of the use and availability of PPE in German EMS personnel during the SARS-CoV-2 pandemic. The secondary objective was to generate additional data on individual perceptions of risk of infection and occurrence of infections at the respective places of service.

\section{Methods}

\subsection{Study Design and Setting}

The survey, a multicentric prospective cohort investigation, was conducted between $1^{\text {st }}$ of March and $1^{\text {st }}$ of April, 2021 via the online survey tool Lime Survey (Version 4.5.2 + 210426). The survey questions were developed by the IRuN in collaboration with the Robert Koch-Institute (RKI), Berlin. Questions focused on availability and use of PPE, quarantining and COVID-19 infections among EMS staff.

Ahead of the distribution of the survey, a test version was shared with a small group of peers who had not been involved in the survey design. Their remarks were taken into consideration when finalizing the survey.

The survey was conducted at two levels-EMS managers and medical and paramedical EMS employees-with questions adapted slightly to fit the respective study population. This design was chosen to be able to compare whether assessments and experiences at the managerial level corresponded to those of the employees.

The questionnaire aimed at the EMS managers contained 15 questions, whereas the one for EMS employees contained 19 questions.

Responses were collected anonymously except for the first digit of the postal code. This data helped identify whether responses were received from across the nation.

Specifically for EMS managers, the size of the EMS area of operation (in size categories) was queried. Specifically for EMS employees, age (in age categories) and gender were asked.

This data was collected to potentially be able to design more specific and appropriate recommendations at a later stage.

\subsection{Study Population}

The survey was designed for German EMS managers and EMS employees. Participation in the survey was voluntary. To reach the desired study population, the survey was distributed via specific channels, which are detailed in the following paragraphs for both groups.

To recruit participants from the group of EMS managers, the contact databases of the IRuN were used, which contain details of medical directors of EMS services (Ärztlicher Leiter Rettungsdienst) for each region in Germany. A total of 150 personalized invitations were sent out. Participation in this group was only 
possible by entering a personalized code received via e-mail.

To recruit participants from the group of EMS employees, a different approach was used to get maximum participation in the survey. The questionnaire was made available openly and shared via social media channels focusing specifically on emergency medicine, existing EMS contacts from the Institute's database, and personal contacts in various EMS.

A minimum sample size of 325 participants in the group of EMS employees was needed to conduct the goodness of fit test (effect size 0.2; $\alpha=0.05 ; \mathrm{df}=1$; power $=0.95)$ and to show the differences in mask use between paramedical and medical staff.

\subsection{Data Protection}

Data was collected via the online survey tool Lime Survey (Version 4.5.2+ 210426) hosted on a server in Germany. Answers for both groups were anonymized automatically through the survey tool. This was done to ensure that no correlation between the personalized invitations and the respective responses could be made. No personal data of study participants which could be used to draw conclusions about their identity was collected. After completion of the survey, the collected data was imported into Microsoft $^{\oplus}$ Excel $^{\circledR}$ (V.1808; 2019 MSO), as well as IBM SPSS Statistics V.26 and evaluated. The data evaluation took place in Germany.

\subsection{Ethical Considerations}

The survey was approved by the University of Kiel ethics committee (D422/21). Information about the purpose of the survey and the use of participants' anonymized answers was given on the welcome page of the survey. Participants were advised that by proceeding, they would consent to their answers being used for further analysis and publications.

\subsection{Analysis}

Descriptive analysis on absolute and relative frequencies was performed for the data on PPE availability and use, both when attending to patients and at the EMS station, as well as the estimates of infected or quarantined staff. PPE use was further divided into encounters with patients with confirmed, suspected or no indication of a SARS-CoV-2 infection. The $\chi^{2}$ goodness-of-fit-test was used to evaluate whether mask use changed according to the SARS-CoV-2 infection category and depending on the type of EMSstaff-paramedical or medical. The test was completed with $\mathrm{df}=1$ and $\alpha=0.05$.

\section{Results}

\subsection{Respondents and Respondent Rates}

A total of 34 responses were received in the managerial group, whereas a total of 2389 responses were received in the group of employees. Of these, 28 and 2078 
answers were considered complete, respectively.

150 invitations were sent out in the managerial group. With 28 complete answers received, $18.7 \%$ of the targeted persons responded. Judging from the first digits of the postal codes submitted, answers were received from all federal states of Germany. Half of the respondents $(50.0 \%, \mathrm{n}=14)$ in this group stated their EMS area of operation employed 300 or more staff. $25.0 \%(n=7)$ were responsible for 100 to 199 employees, followed by $14.3 \%$ from areas of operation with 200 to $299(n=4)$, and $10.7 \%$ with less than $100(n=3)$ employees.

In the survey for EMS employees, of the 2078 persons that responded to the question on profession, $80.8 \%(n=1678)$ stated they belonged to the group of paramedical staff, whereas $19.2 \%(n=400)$ stated they were Medical Doctors. Regarding overall gender distribution, $22.0 \%(n=454)$ of respondents were female, $0.1 \%(n=2)$ diverse and $77.9 \%(n=1612)$ male.

Due to the nature of the study, representativeness of this group can only be approximated by comparing the results to similar historical studies that focused on the same study population and had a similar size.

A study conducted in 2017 [21] among 714 German EMS personnel stated a gender distribution of $17.7 \%$ female and $82.3 \%$ male whereas a more recent study conducted in 2021 [22] stated a distribution of $21.8 \%$ female and $78.2 \%$ male. Two other studies examined just Emergency Medical Doctors [23] (22.2\% female, $77.7 \%$ male) and paramedical staff [24] (13.8\% female, $86.2 \%$ male). The results of these studies were similar to the present survey with $27.8 \%(n=110)$ female and 72.2\% $(\mathrm{n}=285)$ male emergency doctors and 20.6\% ( $\mathrm{n}=344)$ female, $79.3 \%(n=1327)$ male, and $0.1 \%(n=2)$ diverse paramedical staff.

Regarding age distribution the most recent comparable study [22] found a very similar age distribution to the present survey with $30 \%$ being 18 - 29 years (present study: $34.2 \%, \mathrm{n}=708$ ), 33.8\% $30-39$ years (present study: $30.6 \%, \mathrm{n}=$ 634), $21.7 \%$ being 40 - 49 years (present study: $21.1 \%, \mathrm{n}=437$ ), $12 \%$ being 50 59 years (present study: $11.4 \%, \mathrm{n}=236$ ) and $1.5 \%$ being $60-69$ years (present study: answers on age 60 or above: $2.3 \%, \mathrm{n}=57$ ). Another study focusing only on paramedical staff [24] also stated very similar age demographics to the present study.

Answers were received from all federal states of Germany judging from the first digits of the postal codes submitted.

Overall, the demographic data distribution of EMS employee respondents compares to those of previous studies focusing on the same study population.

See Figure 1 for the overview on general respondent data for both EMS managers and employees.

\subsection{Mandatory PPE}

Of the 28 EMS managers that responded to the survey, all (100.0\%) stated that gloves, protective gown or coveralls, and FFP2 ${ }^{1}$ or FFP $3^{2}$ masks had to be worn ${ }^{1}$ At least $94 \%$ filtration capacity, similar to N95 mask.

${ }^{2}$ At least $99 \%$ filtration capacity, similar to N99 mask. 

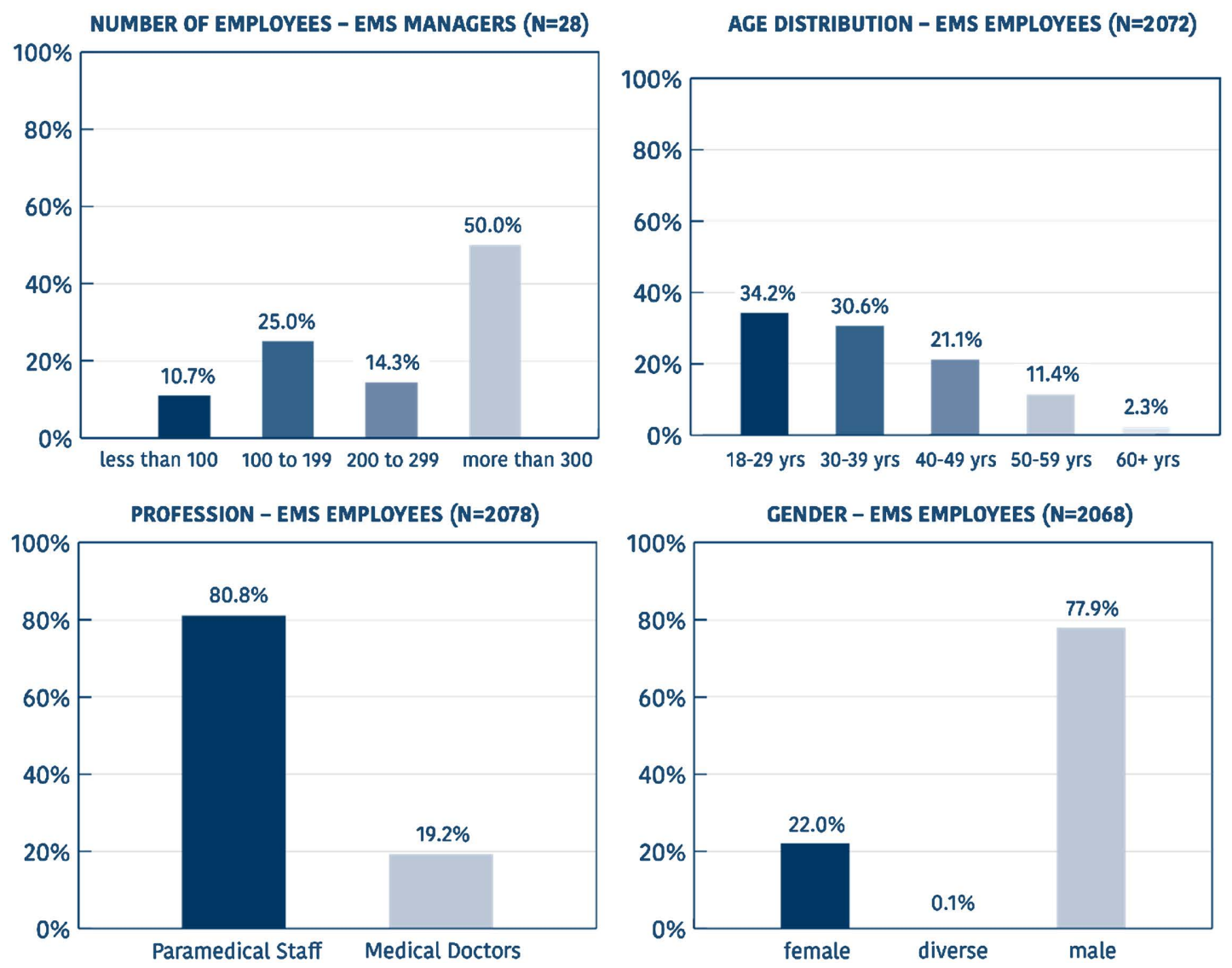

Figure 1. Study population data.

in their area of operation when attending to SARS-CoV-2 positive patients. Goggles were stated as mandatory in $96.4 \%(n=27)$ of cases, whereas $35.7 \%(n=$ $10)$ replied that face shields had to be worn. None $(0.0 \%)$ stated that simple surgical masks were mandatory (Table 1).

In terms of mandatory PPE for suspected SARS-CoV-2 positive patients, answers changed slightly. Recommendations to use surgical masks $(0.0 \%)$ and face shields $(35.7 \%, \mathrm{n}=10)$ remained the same. Mandatory use of gloves, as well as FFP2 or FFP3 masks dropped to $96.4 \%(n=27)$ and use of protective gown or coveralls to $92.8 \%(n=26)$. Answers on the use of goggles dropped even further to $82.1 \%(\mathrm{n}=23)$ (Table 1$)$.

Regarding mandatory PPE when attending to patients with no signs of a SARS-CoV-2 infection, figures changed more significantly with $92.9 \%(\mathrm{n}=26)$ stating mandatory use of gloves and $89.3 \%(n=25)$ FFP2 or FPP3 masks. Only $3.6 \%(n=1)$ respectively stated that gowns or coveralls, surgical masks and face shields had to be used. Finally, 32.1\% $(n=9)$ stated that goggles were mandatory when attending to these types of patients (Table 1 ).

\subsection{Use and availability of PPE}

For the EMS employees, among the 2078 staff that responded, the majority stated that when attending to SARS-CoV-2 positive patients, they wear gloves 
Table 1. Mandatory PPE according to EMS managers.

\begin{tabular}{|c|c|c|c|c|}
\hline $\begin{array}{l}\text { Which protective equipment is mandatory when } \\
\text { attending to a SARS-CoV-2 positive patient? }(n=28)\end{array}$ & $\begin{array}{c}\text { Absolute } \\
\text { Frequency } \\
\text { "Yes" }\end{array}$ & $\begin{array}{l}\text { Relative } \\
\text { Frequency } \\
\text { "Yes" }\end{array}$ & $\begin{array}{c}\text { Absolute } \\
\text { Frequency } \\
\text { "No" }\end{array}$ & $\begin{array}{c}\text { Relative } \\
\text { Frequency } \\
\text { "No" }\end{array}$ \\
\hline Gloves & 28 & $100.0 \%$ & 5 & $17.9 \%$ \\
\hline Protective Gown & 17 & $60.7 \%$ & 11 & $39.3 \%$ \\
\hline Coveralls & 11 & $39.3 \%$ & 17 & $60.7 \%$ \\
\hline Surgical Mask & 0 & $0.0 \%$ & 0 & $0.0 \%$ \\
\hline FFP2-Mask & 11 & $39.3 \%$ & 17 & $60.7 \%$ \\
\hline FFP3-Mask & 9 & $32.1 \%$ & 19 & $67.9 \%$ \\
\hline FFP2- or FFP3-Mask (depending on availability) & 8 & $28.6 \%$ & 20 & $71.4 \%$ \\
\hline Goggles & 27 & $96.4 \%$ & 1 & $3.6 \%$ \\
\hline Face Shield & 10 & $35.7 \%$ & 18 & $64.3 \%$ \\
\hline $\begin{array}{l}\text { Which protective equipment is mandatory when attending } \\
\text { to a suspected SARS-CoV-2 positive patient? }(n=28)\end{array}$ & $\begin{array}{c}\text { Absolute } \\
\text { Frequency } \\
\text { "Yes" }\end{array}$ & $\begin{array}{l}\text { Relative } \\
\text { Frequency } \\
\text { "Yes" }\end{array}$ & $\begin{array}{c}\text { Absolute } \\
\text { Frequency } \\
\text { "No" }\end{array}$ & $\begin{array}{l}\text { Relative } \\
\text { Frequency } \\
\text { "No" }\end{array}$ \\
\hline Gloves & 27 & $96.4 \%$ & 1 & $3.6 \%$ \\
\hline Protective Gown & 20 & $71.4 \%$ & 8 & $28.6 \%$ \\
\hline Coveralls & 6 & $21.4 \%$ & 22 & $78.6 \%$ \\
\hline Surgical Mask & 0 & $0.0 \%$ & 28 & $100.0 \%$ \\
\hline FFP2-Mask & 17 & $60.7 \%$ & 11 & $39.3 \%$ \\
\hline FFP3-Mask & 6 & $21.4 \%$ & 22 & $78.6 \%$ \\
\hline FFP2- or FFP3-Mask (depending on availability) & 4 & $14.3 \%$ & 24 & $85.7 \%$ \\
\hline Goggles & 23 & $82.1 \%$ & 5 & $17.9 \%$ \\
\hline Face Shield & 10 & $35.7 \%$ & 18 & $64.3 \%$ \\
\hline $\begin{array}{l}\text { Which protective equipment do you put on when attending to } \\
\text { a patient who does not show signs of SARS-CoV-2? }(n=28)\end{array}$ & $\begin{array}{c}\text { Absolute } \\
\text { Frequency } \\
\text { "Yes" }\end{array}$ & $\begin{array}{l}\text { Relative } \\
\text { Frequency } \\
\text { "Yes" }\end{array}$ & $\begin{array}{c}\text { Absolute } \\
\text { Frequency } \\
\text { "No" }\end{array}$ & $\begin{array}{l}\text { Relative } \\
\text { Frequency } \\
\text { "No" }\end{array}$ \\
\hline Gloves & 26 & $92.9 \%$ & 2 & $7.1 \%$ \\
\hline Protective Gown & 1 & $3.6 \%$ & 27 & $96.4 \%$ \\
\hline Coveralls & 0 & $0.0 \%$ & 28 & $100.0 \%$ \\
\hline Surgical Mask & 1 & $3.6 \%$ & 27 & $96.4 \%$ \\
\hline FFP2-Mask & 24 & $85.7 \%$ & 4 & $14.3 \%$ \\
\hline FFP3-Mask & 0 & $0.0 \%$ & 28 & $100.0 \%$ \\
\hline FFP2- or FFP3-Mask (depending on availability) & 1 & $3.6 \%$ & 27 & $96.4 \%$ \\
\hline Goggles & 9 & $32.1 \%$ & 19 & $67.9 \%$ \\
\hline Face Shield & 1 & $3.6 \%$ & 27 & $96.4 \%$ \\
\hline
\end{tabular}


(99.8\%, n = 2073), FFP2 or FFP3 mask (total: 99.8\%, $\mathrm{n}=2073)$, protective gown or coveralls (total: $99.1 \%, \mathrm{n}=2060)$ and goggles $(89.7 \%, \mathrm{n}=1863)$. Face shields $(24.0 \%, \mathrm{n}=498)$ and surgical masks $(0.0 \%)$ were the equipment least cited when attending to a SARS-CoV-2 positive patient (Table 2).

The figures changed slightly when respondents were faced with the question on PPE use for suspected SARS-CoV-2 positive patients. The stated use of gloves (98.8\%, $\mathrm{n}=2053)$, FFP2 or FFP3 masks (total: $99.4 \%, \mathrm{n}=2065)$ and surgical masks $(0.2 \%, \mathrm{n}=4)$ remained on a similar level. However, use of gowns or coveralls (total: $95.9 \%, \mathrm{n}=1993)$, goggles $(85.6 \%, \mathrm{n}=1778)$ and face shields $(19.2 \%, \mathrm{n}$ $=400$ ) decreased slightly (Table 2).

When attending to patients without signs of SARS-CoV-2, answers changed more significantly in several categories. Use of gloves $(95.7 \%, \mathrm{n}=1988)$, FFP2 or FFP3 masks (total: $97.5 \%, \mathrm{n}=2026)$ and surgical masks $(1.5 \%, \mathrm{n}=31$ ) remained on a similar level to the previous questions. However, use of protective gowns or coveralls (total: $5.9 \%, \mathrm{n}=122)$, goggles $(36.9 \%, \mathrm{n}=766)$ and face shields $(2.6 \%$, $\mathrm{n}=53$ ) all dropped to much lower levels (Table 2).

See Figure 2 for an overview of the answers of EMS managers and employees on PPE use.

The total use of both FFP2 and FFP3 masks was further analyzed to determine whether there were differences in mask use between paramedical and medical staff. For PPE use in a SARS-CoV-2 positive patient (Table 3 ), the $\chi^{2}$ result showed an asymptotic significance of 0.231 . For PPE use in a SARS-CoV-2 negative patient (Table 3 ), the $\chi^{2}$ result showed an asymptotic significance of 0.155 .

In terms of the availability of PPE, the majority of respondents $(75.3 \%, \mathrm{n}=$ 1524) stated that at the beginning of the pandemic there was not enough PPE available at their workplace $(\mathrm{n}=2024)$. In comparison, at the time of answering the survey, the majority of EMS employees $(87.6 \%, n=1783)$ stated that they were of the opinion that there was now enough PPE available at their workplace $(\mathrm{n}=2035)$.

EMS managers were only asked whether they were of the impression that there was now enough PPE available in their EMS area of operation. 26 respondents $(92.8 \%)$ confirmed that - according to them - this was the case. Two EMS managers skipped this question.

\subsection{Mask use at the EMS Station}

Concerning the mask used at the EMS station, 43.4\% ( $n=903)$ of the 2,053 EMS employee respondents stated that they regularly wear a FFP2 mask at their station, whereas $42.2 \%(n=877)$ responded that they wear a surgical mask. $5.1 \%(n$ $=105)$ stated they do not wear any mask, 5.0\% $(n=103)$ replied that they are stationed at a base and keeping their distance is not an issue, and 2.0\% ( $n=42)$ said staff teams are seen as a cohort and therefore do not need to wear a mask. $0.5 \%(\mathrm{n}=11)$ do not wear a mask since they are being tested at the start of their shifts, $0.5 \%(n=10)$ stated that they wear a cloth mask, whilst $0.1 \%(n=2)$ wear a FFP3 mask 0.25 (1.2\%) EMS employees did not answer the question. 
Table 2. Use of PPE according to EMS employees.

\begin{tabular}{|c|c|c|c|c|}
\hline $\begin{array}{l}\text { Which protective equipment do you put on when attending to } \\
\text { a SARS-CoV-2 positive patient? }(n=2078)\end{array}$ & $\begin{array}{l}\text { Absolute } \\
\text { Frequency } \\
\text { "Yes" }\end{array}$ & $\begin{array}{l}\text { Relative } \\
\text { Frequency } \\
\text { "Yes" }\end{array}$ & $\begin{array}{l}\text { Absolute } \\
\text { Frequency } \\
\text { "No" }\end{array}$ & $\begin{array}{l}\text { Relative } \\
\text { Frequency } \\
\text { "No" }\end{array}$ \\
\hline Gloves & 2073 & $99.8 \%$ & 5 & $0.2 \%$ \\
\hline Protective Gown & 1193 & $57.4 \%$ & 885 & $42.6 \%$ \\
\hline Coveralls & 867 & $41.7 \%$ & 1211 & $58.3 \%$ \\
\hline Surgical Mask & 1 & $0.0 \%$ & 2077 & $100.0 \%$ \\
\hline FFP2-Mask & 1138 & $54.8 \%$ & 940 & $45.2 \%$ \\
\hline FFP3-Mask & 317 & $15.3 \%$ & 1761 & $84.7 \%$ \\
\hline FFP2- or FFP3-Mask (depending on availability) & 617 & $29.7 \%$ & 1461 & $70.3 \%$ \\
\hline Goggles & 1863 & $89.7 \%$ & 215 & $10.3 \%$ \\
\hline Face Shield & 498 & $24.0 \%$ & 1580 & $76.0 \%$ \\
\hline $\begin{array}{l}\text { Which protective equipment do you put on when attending to } \\
\text { a suspected SARS-CoV-2 positive patient? }(n=2078)\end{array}$ & $\begin{array}{l}\text { Absolute } \\
\text { Frequency } \\
\text { "Yes" }\end{array}$ & $\begin{array}{l}\text { Relative } \\
\text { Frequency } \\
\text { "Yes" }\end{array}$ & $\begin{array}{l}\text { Absolute } \\
\text { Frequency } \\
\text { "No" }\end{array}$ & $\begin{array}{l}\text { Relative } \\
\text { Frequency } \\
\text { "No" }\end{array}$ \\
\hline Gloves & 2053 & $98.8 \%$ & 25 & $1.2 \%$ \\
\hline Protective Gown & 1443 & $69.4 \%$ & 635 & $30.6 \%$ \\
\hline Coveralls & 550 & $26.5 \%$ & 1528 & $73.5 \%$ \\
\hline Surgical Mask & 4 & $0.2 \%$ & 2074 & $99.8 \%$ \\
\hline FFP2-Mask & 1341 & $64.5 \%$ & 737 & $35.5 \%$ \\
\hline FFP3-Mask & 205 & $9.9 \%$ & 1873 & $90.1 \%$ \\
\hline FFP2- or FFP3-Mask (depending on availability) & 519 & $25.0 \%$ & 1559 & $75.0 \%$ \\
\hline Goggles & 1778 & $85.6 \%$ & 300 & $14.4 \%$ \\
\hline Face Shield & 400 & $19.2 \%$ & 1678 & $80.8 \%$ \\
\hline $\begin{array}{l}\text { Which protective equipment do you put on when attending to } \\
\text { a patient who does not show signs of SARS-CoV-2? }(n=2078)\end{array}$ & $\begin{array}{l}\text { Absolute } \\
\text { Frequency } \\
\text { "Yes" }\end{array}$ & $\begin{array}{l}\text { Relative } \\
\text { Frequency } \\
\text { "Yes" }\end{array}$ & $\begin{array}{l}\text { Absolute } \\
\text { Frequency } \\
\text { "No" }\end{array}$ & $\begin{array}{l}\text { Relative } \\
\text { Frequency } \\
\text { "No" }\end{array}$ \\
\hline Gloves & 1988 & $95.7 \%$ & 90 & $4.3 \%$ \\
\hline Protective Gown & 105 & $5.1 \%$ & 1973 & $94.9 \%$ \\
\hline Coveralls & 17 & $0.8 \%$ & 2061 & $99.2 \%$ \\
\hline Surgical Mask & 31 & $1.5 \%$ & 2047 & $98.5 \%$ \\
\hline FFP2-Mask & 1741 & $83.8 \%$ & 337 & $16.2 \%$ \\
\hline FFP3-Mask & 27 & $1.3 \%$ & 2051 & $98.7 \%$ \\
\hline FFP2- or FFP3-Mask (depending on availability) & 258 & $12.4 \%$ & 1820 & $87.6 \%$ \\
\hline Goggles & 766 & $36.9 \%$ & 1312 & $63.1 \%$ \\
\hline Face Shield & 53 & $2.6 \%$ & 2025 & $97.4 \%$ \\
\hline
\end{tabular}



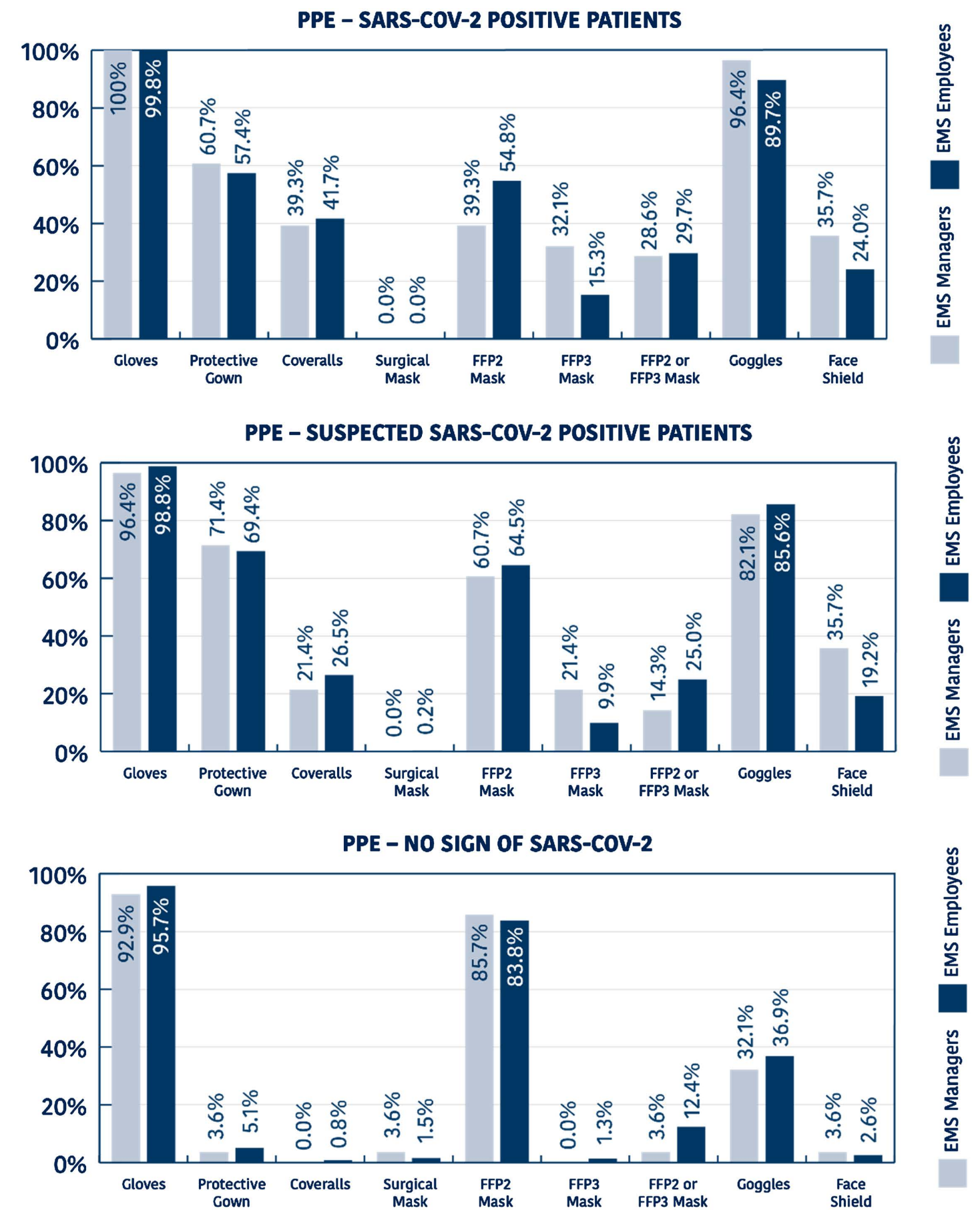

Figure 2. Overview of PPE use.

Table 3. Use of FFP2 or FFP3 masks.

\begin{tabular}{cccc}
\hline Use of FFP2 or FFP3 masks by EMS Employees & & & \\
\hline & $\begin{array}{c}\text { Medical Doctor-Answer: Yes } \\
(\mathrm{n}=400)\end{array}$ & $\begin{array}{c}\text { Paramedical Staff-Answer: Yes } \\
(\mathrm{n}=2078)\end{array}$ & p-Value \\
\hline SARS-CoV-2 positive patient & 400 & 2072 & $0.231^{\star}$ \\
No sign of SARS-CoV-2 infection & 386 & 2062 & $0.115^{\star}$ \\
\hline
\end{tabular}




\subsection{SARS-CoV-2 Infections and Quarantine}

27 respondents (96.4\%) in the EMS managers group stated that there had been SARS-CoV-2 cases at their EMS area of operation. One person did not answer the question.

Regarding quarantine, $53.6 \%(n=15)$ stated less than $5 \%$ of their employees had been quarantined due to an occupational SARS-CoV-2 contact. $21.4 \%$ ( $\mathrm{n}=$ 6) estimated the number of quarantined staff at $5 \%$ to $10 \%$, whereas $3.7 \%(n=1)$ estimated this figure at $30 \%$ to $40 \% .3 .6 \%(n=1)$ responded that none of their employees had to quarantine due to an occupational contact and $14.3 \%(\mathrm{n}=4)$ did not know. One person did not answer the question.

In contrast, $62.1 \%(\mathrm{n}=1291)$ of EMS employees stated that there had been SARS-CoV-2 cases at their EMS station. The number of staff who stated that they had been infected themselves was 122 (5.9\%). 12 EMS employees skipped this question.

Of 2060 EMS employees that answered the question on whether they had been in quarantine at least once themselves due to an occupational contact, only 448 (21.6\%) answered "Yes". 18 EMS employees decided to not answer this question.

Finally, out of the $21.6 \%$ stating that they had been quarantined, $46.9 \%$ ( $\mathrm{n}=$ 210) answered that this was due to contact with a patient or relative of the patient, $17.5 \%(n=76)$ stated that it varied and $34.4 \%(n=154)$ responded that their quarantine was not due to contact with a patient or relative.

\section{Discussion}

The above results show high self-reported adherence to PPE of German EMS employees during the SARS-CoV-2 pandemic. However, there is a general lack of studies analyzing PPE use in German EMS employees before the onset of the SARS-CoV-2 pandemic. International studies conducted before the SARS-CoV-2 pandemic often observed a general lack of adherence to PPE protocols in EMS workers [16] [18].

Behavior was self-reported in the survey and despite it being anonymous, it might not be coherent with day-to-day practices. This was reported previously in other studies where self-reported behavior and actual behavior were not congruent [25].

The RKI has released general recommendations concerning PPE for healthcare workers, which state that the following should be worn when attending to a suspect or confirmed SARS-CoV-2 positive patient: protective gown, gloves, mask (minimum FFP2 when directly caring for suspected or confirmed positive cases, simple surgical masks are not seen as providing enough protection) and goggles [26]. However, these are recommendations only. There are no PPE guidelines for EMS workers that are applicable nationwide.

Looking at the responses from EMS managers regarding mandatory PPE for SARS-CoV-2 positive and suspected SARS-CoV-2 positive patients, all of them agreed with the above recommendation that gloves, protective gowns or cove- 
ralls and FPP2 or FFP3 masks had to be worn when attending to SARS-CoV-2 positive patients. Only the stated use of goggles was not in line with the recommendations.

When attending to suspected SARS-CoV-2 positive patients, the EMS managers however did not fully agree with the above, with all stated use of recommended PPE dropping to below $100 \%$.

As for the EMS employees, self-reported adherence to the RKI recommendations and guidance from EMS managers when attending to confirmed SARS-CoV-2 patients is good. Over $99 \%$ of staff state to be using gloves, FFP2 or FFP3 masks as well as protective gowns or coveralls when attending to this patient group. Only the use of goggles is reported at a lower level.

When attending to suspected SARS-CoV-2 positive patients, adherence to the recommendations drops slightly. Whereas the use of gloves and FFP2 or FFP3 masks remains at over 98\%, the reported use of gowns or coveralls and the use of goggles is reduced further.

Previous studies have found that the use of gloves has generally been good in EMS staff [16], whereas the use of protective masks left room for improvement [20]. This does not seem to be coherent with the findings of this study, indicating that since the beginning of the SARS-CoV-2 pandemic mask use of EMS staff has been improved.

One thing that stands out from the survey is that the use of goggles in both confirmed and suspected SARS-CoV-2 patients is neither recommended by all EMS managers nor stated as being used by EMS employees. This is something that should be looked at and recommendations and behaviour ideally adjusted, since transmission of the virus does occur via infected secretions, such as droplets, which can be absorbed via the mucosal skin of the eyes [27].

A possible explanation for the stated low percentage of use of goggles could also be that guidelines of certain EMS providers are not in line with the recommendations of the RKI and in certain cases, face shields are used instead of goggles.

An additional important point for EMS managers and employees to note is that the recommendation on PPE use for suspected SARS-CoV-2 patients by the RKI is the same as for confirmed patients. Adherence to these recommendations was found to be less than $100.0 \%$ in the findings of the survey. Again, this should be monitored and if possible guidelines and behaviour adjusted, in order to ensure the best possible protection of EMS staff.

Another aspect analyzed was difference in mask use between medical and paramedical staff. According to the participant's answers, there is no significant difference between mask use in paramedical or medical staff-whether the patient attended to is SARS-CoV-2 positive or not.

On $30^{\text {th }}$ of April, 2021, according to the German RKI, a total of 3,381,597 people were infected with the SARS-CoV-2 virus in Germany [28]. This equates to approximately $4.0 \%$ of the German population. 
EMS staff have a high likelihood of getting infected with SARS-CoV-2 due to their occupational exposure risk. Nonetheless, the low number of staff (5.9\%) stating that they had been infected with SARS-CoV-2 themselves, which is only slightly higher than the overall infection rates within the German population, could support the assumption that the adherence to PPE use recommendations is good within the EMS workforce.

Since the date of infection was not requested in the survey, no conclusions can be drawn from the reported lack of PPE at the beginning of the pandemic in 2020 and the number of infections that might have resulted from this. In addition, no data was collected on whether staff who had been infected with SARS-CoV-2 contracted the disease at their place of work.

Another result that could potentially support the indicated good use of PPE when attending to patients is regarding quarantine. Over a third of EMS staff who had to quarantine due to an occupational contact responded that this was not due to contact with a patient or a patient's relative. A possible explanation for this could be that during contact with patients or their relatives, proper PPE was worn and that therefore, the above staff were not in proper PPE when in contact with the person due to which they had to quarantine.

When in contact with colleagues at the EMS station, most staff stated they were either wearing a surgical or FFP2 mask. The use of surgical masks at places of work in Germany was legally deemed necessary on the $21^{\text {st }}$ of January, 2021 [29]. A total of $13.1 \%$ of EMS employees stated that they wear cloth masks or no masks at all at the EMS station.

The survey however does not show a correlation between lacks of PPE or mask use at the EMS station and staff quarantine. This is something that should be investigated further.

\section{Limitations}

Recruitment of EMS employees was done via an open invitation on social media, existing contacts from the institute's database, and through personal contacts in various rescue services. Participation in the survey was voluntary and selection effects cannot be ruled out. However, the demographic data of respondents is comparable to previous studies focusing on the same study population. Therefore, we assume that selection effects have not distorted the results.

\section{Conclusion}

Overall, the survey points to German EMS staff using proper PPE and protecting themselves well during the current SARS-CoV-2 pandemic. More research needs to be done on this topic, also conducting observational studies to confirm the self-declared statements of staff. If confirmed, another interesting aspect to focus on would be the reasons for improved use of PPE compared to previous studies. This information could inform how education, training and health promotion on PPE use for EMS workers could be communicated in the future in order to 
better protect EMS staff.

\section{Declarations}

\section{Ethics Approval and Consent to Participate}

The survey was approved by the University of Kiel ethics committee (D422/21). Information about the purpose of the survey and the use of participants' anonymized answers was given on the welcome page of the survey.

\section{Consent for Publication}

Information about the purpose of the survey and the use of participants' anonymized answers was given on the welcome page of the survey. Participants were advised that by proceeding, they would consent to their answers being used for further analysis and publications.

\section{Availability of Data and Materials}

All data relevant to the study are included in this published article.

\section{Authors' Contributions}

JTG and JW conceived of the study. TB drafted the protocol, which was reviewed by JTG, JW, MZ and JK. JK drafted the survey questions, which were reviewed by JTG, JW, MZ, LH and TB. MZ implemented the survey online. TB prepared and analyzed the data, which was reviewed by JTG, JW, MZ, JK and BA. The final manuscript was drafted by TB and reviewed and approved by all contributors.

\section{Acknowledgements}

We thank Univ.-Prof. Dr. Lefering for his guidance and support on data and statistics for this article. We also thank Hanna-Joy Renner for carefully reviewing the manuscript.

\section{Conflicts of Interest}

The authors declare no conflicts of interest regarding the publication of this paper.

\section{References}

[1] Spiteri, G., Fielding, J., Diercke, M., et al. (2020) First Cases of Coronavirus Disease 2019 (COVID-19) in the WHO European Region, 24 January to 21 February 2020. Eurosurveillance, 25, Article ID: 2000178. https://doi.org/10.2807/1560-7917.ES.2020.25.9.2000178

[2] Koch-Institut, R. (2021) Epidemiologischer Steckbrief zu SARS-CoV-2 und COVID-19. Berlin.

https://www.rki.de/DE/Content/InfAZ/N/Neuartiges_Coronavirus/Steckbrief.html;j sessionid $=483838483838$ D10EF66AE204EA05813B.internet122? $\mathrm{nn}=13490888 \#$ doc 1 
3776792bodyText1

[3] Mutambudzi, M., Niedwiedz, C., Macdonald, E.B., et al. (2020) Occupation and Risk of Severe COVID-19: Prospective Cohort Study of 120075 UK Biobank Participants. Occupational and Environmental Medicine, 78, 307-314. https://doi.org/10.1136/oemed-2020-106731

[4] Kua, J., Patel, R., et al. (2021) Healthcare COVID: A National Cross-Sectional Observational Study Identifying Risk Factors for Developing Suspected or Confirmed COVID-19 in UK Healthcare Workers. PeerJ, 9, e10891. https://doi.org/10.7717/peerj.10891

[5] Shah, A.S.V., Wood, R., Gribben, C., et al. (2020) Risk of Hospital Admission with Coronavirus Disease 2019 in Healthcare Workers and Their Households: Nationwide Linkage Cohort Study. BMJ, 371, m3582. https://doi.org/10.1136/bmj.m3582

[6] Schneider, S., Piening, B., Nouri-Pasovsky, P.A., et al. (2020) SARS-Coronavirus-2 Cases in Healthcare Workers May Not Regularly Originate from Patient Care: Lessons from a University Hospital on the Underestimated Risk of Healthcare Worker to Healthcare Worker Transmission. Antimicrobial Resistance \& Infection Control, 9, 192. https://doi.org/10.1186/s13756-020-00848-w

[7] Centres for Disease Control and Prevention (2021) Cases \& Deaths among Healthcare Personnel. Atlanta.

https://covid.cdc.gov/covid-data-tracker/?CDC_AA_refVal=https $\% 3 \mathrm{~A} \% 2 \mathrm{~F} \% 2 \mathrm{Fww}$ w.cdc.gov $\% 2$ Fcoronavirus $\% 2$ F2019-ncov\%2Fcases-updates $\% 2$ Fcases-in-us.html\#he alth-care-personnel

[8] World Health Organization (2021) Coronavirus Disease 2019 (COVID-19). Situation Report 82. World Health Organization, Geneva.

https://www.who.int/docs/default-source/coronaviruse/situation-reports/20200411sitrep-82-covid-19.pdf

[9] Erdem, H. and Lucey, D.R. (2021) Healthcare Worker Infections and Deaths Due to COVID-19: A Survey from 37 Nations and a Call for WHO to Post National Data on Their Website. International Journal of Infectious Diseases, 102, 239-241. https://doi.org/10.1016/j.ijid.2020.10.064

[10] Bandyopadhyay, S., Baticulon, R.E., Kadhum, M., et al. (2020) Infection and Mortality of Healthcare Workers Worldwide from COVID-19: A Systematic Review. BMJ Global Health, 5, e003097. https://doi.org/10.1136/bmjgh-2020-003097

[11] Bielicki, J.A., Duval, X., et al. (2020) Monitoring Approaches for Health-Care Workers during the COVID-19 Pandemic. The Lancet Infectious Diseases, 20, e261-e267. https://doi.org/10.1016/S1473-3099(20)30458-8

[12] Prezant, D.J., Zeig-Owens, R., Schwartz, T., et al. (2020) Medical Leave Associated with COVID-19 among Emergency Medical System Responders and Firefighters in New York City. JAMA Network Open, 3, e2016094.

https://doi.org/10.1001/jamanetworkopen.2020.16094

[13] Verbeek, P.R., McClelland, I.W., Silverman, A.C., et al. (2004) Loss of Paramedic Availability in an Urban Emergency Medical Services System during a Severe Acute Respiratory Syndrome Outbreak. Academic Emergency Medicine, 11, 973-978. https://doi.org/10.1197/j.aem.2004.03.021

[14] Ko, P.C., Chen, W.J., Ma, M.H., et al. (2004) Emergency Medical Services Utilization during an Outbreak of Severe Acute Respiratory Syndrome (SARS) and the Incidence of SARS-Associated Coronavirus Infection among Emergency Medical Technicians. Academic Emergency Medicine, 11, 903-911.

https://doi.org/10.1197/j.aem.2004.03.016 
[15] Murphy, D.L., Barnard, L.M., Drucker, C.J., et al. (2020) Occupational Exposures and Programmatic Response to COVID-19 Pandemic: An Emergency Medical Services Experience. Emergency Medicine Journal, 37, 707-713. https://doi.org/10.1136/emermed-2020-210095

[16] Bitely, C., Miller, B. and Glauser, J. (2019) EMS Disease Exposure, Transmission, and Prevention: A Review Article. Current Emergency and Hospital Medicine Reports, 7, 135-140. https://doi.org/10.1007/s40138-019-00200-6

[17] Thomas, B., O’Meara, P. and Spelten, E. (2017) Everyday Dangers-The Impact Infectious Disease Has on the Health of Paramedics: A Scoping Review. Prehospital and Disaster Medicine, 32, 217-223. https://doi.org/10.1017/S1049023X16001497

[18] Harris, S.A. and Nicolai, L.A. (2010) Occupational Exposures in Emergency Medical Service Providers and Knowledge of and Compliance with Universal Precautions. American Journal of Infection Control, 38, 86-94.

https://doi.org/10.1016/j.ajic.2009.05.012

[19] Chen, F., Zang, Y., Liu, Y., et al. (2021) Dispatched Nurses' Experience of Wearing Full Gear Personal Protective Equipment to Care for COVID-19 Patients in China-A Descriptive Qualitative Study. Journal of Clinical Nursing, 30, 2001-2014. https://doi.org/10.1111/jocn.15753

[20] Gershon, R.R., Vandelinde, N., Magda, L.A., et al. (2009) Evaluation of a Pandemic Preparedness Training Intervention of Emergency Medical Services Personnel. Prehospital and Disaster Medicine, 24, 508-511. https://doi.org/10.1017/S1049023X00007421

[21] Zimmer, M., Czarniecki, D.M. and Sahm, S. (2021) Communication of Preclinical Emergency Teams in Critical Situations: A Nationwide Study. PLoS ONE, 16, e0250932. https://doi.org/10.1371/journal.pone.0250932

[22] Nohl, A., Afflerbach, C., Lurz, C., Zeiger, S., Weichert, V., Brade, M., et al. (2021) COVID-19: Acceptance and Compliance of PPE (Personal Protective Equipment) and Rules for Hygiene and Reducing Contacts in German Emergency Medical Services-A Nationwide Survey. Notfall und Rettungsmedizin, 1-8.

[23] Warnecke, T., Dobbermann, M., Becker, T., Bernhard, M. and Hinkelbein, J. (2018) Performance of Prehospital Emergency Anesthesia and Airway Management: An Online Survey. Anaesthesist, 67, 654-663.

https://doi.org/10.1007/s00101-018-0466-x

[24] Baier, N., Roth, K., Felgner, S. and Henschke, C. (2018) Burnout and Safety Outcomes-A Cross-Sectional Nationwide Survey of EMS-Workers in Germany. BMC Emergency Medicine, 18, Article No. 24. https://doi.org/10.1186/s12873-018-0177-2

[25] Emanuelsson, L., Karlsson, L., Castren, M., et al. (2013) Ambulance Personnel Adherence to Hygiene Routines: Still Protecting Ourselves But Not the Patient. European Journal of Emergency Medicine, 20, 281-285.

https://doi.org/10.1097/MEJ.0b013e328357938e

[26] Robert Koch-Institut (2021) Empfehlungen des RKI zu Hygienemaßnahmen im Rahmen der Behandlung und Pflege von Patienten mit einer Infektion durch SARS-CoV-2. Berlin.

https://www.rki.de/DE/Content/InfAZ/N/Neuartiges_Coronavirus/Hygiene.html,js essionid=0ECE5926FB0600AE62282C8D31AB5D18.internet112? $\mathrm{nn}=13490888 \# \mathrm{~h}$

[27] World Health Organization (2020) Transmission of SARS-CoV-2: Implications for Infection Prevention Precautions. Scientific Brief. World Health Organization, Geneva.

https://www.who.int/news-room/commentaries/detail/transmission-of-sars-cov-2-i 
$\underline{\text { mplications-for-infection-prevention-precautions }}$

[28] Robert Koch-Institut (2021) COVID-19 Dashboard. Robert Koch-Institut, Berlin. https://experience.arcgis.com/experience/478220a4c454480e823b17327b2bf1d4

[29] Bundesamt für Justiz (2021) SARS-CoV-2-Arbeitsschutzverordnung. In: Bundesministerium der Justiz und für Verbraucherschutz, ed. BAnz AT 22.01.2021 V1 ed.

\section{List of Abbreviations}

COVRIIN COVID-19 Expert Working Group Intensive Care, Infectiology and Emergency Medicine

EMS Emergency Medical Services

IRuN Institute for Emergency Medicine, Kiel

PPE Personal Protective Equipment

RKI Robert Koch-Institute

WHO World Health Organization 


\section{Appendices}

\section{Survey EMS Managers}

\section{Demographic Data}

1) Please state the first digit of the postcode of your EMS area of operation.

\begin{tabular}{|l|l|l|l|l|}
\hline 0 & 1 & 2 & 3 & 4 \\
\hline 5 & 6 & 7 & 8 & 9 \\
\hline
\end{tabular}

2) Please state the number of employees in your EMS area of operation.

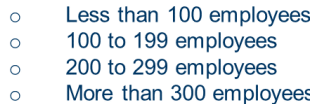

\section{Survey regarding personal protective equipment (PPE) during the}

\section{COVID-19 pandemic}

3) Which protective equipment is mandatory when attending to a SARS-CoV-2 positive patient? (multiple answers possible)

$$
\begin{aligned}
& \text { Gloves } \\
& \text { Protective Gown } \\
& \text { Coveralls } \\
& \text { Surgical Mask } \\
& \text { FFP2-Mask } \\
& \text { FFP3-Mask } \\
& \text { FFP2- or FFP3-Mask (depending on availability) } \\
& \text { Goggles } \\
& \text { Face Shield }
\end{aligned}
$$

4) Which protective equipment is mandatory when attending to a suspected SARS-CoV-2 patient? (multiple answers possible)

$\begin{array}{ll}\circ & \text { Gloves } \\ \circ & \text { Protective Gown } \\ \circ & \text { Coveralls } \\ \circ & \text { Surgical Mask } \\ \circ & \text { FFP2-Mask } \\ \circ & \text { FFP3-Mask } \\ \circ & \text { FFP2- or FFP3-Mask (depending on availability) } \\ \circ & \text { Goggles } \\ \circ & \text { Face Shield }\end{array}$

5) Which protective equipment is mandatory when attending to a patient who does not any show signs of SARS-CoV-2? (multiple answers possible)

Gloves
Protective Gown
Coveralls
Surgical Mask
FFP2-Mask
FFP3-Mask
FFP2- or FFP3-Mask (depending on availability)
Goggles
Face Shield

6) In your opinion, is there currently a sufficient amount of PPE available in your EMS area of operation?

$$
\text { - Yes }
$$$$
\text { - No }
$$

7) Were there SARS-CoV-2 cases within the workforce of your EMS area of operation?

$$
\begin{array}{ll}
\circ & \text { Yes } \\
\circ & \text { No } \\
- & \text { I don't know/no answer }
\end{array}
$$

8) How many employees were quarantined once or multiple times due to an occupational SARS-CoV-2 contact?

$$
\begin{array}{ll}
\circ & \text { None } \\
\circ & \text { Less than } 5 \% \\
\circ & 5 \text { to } 10 \% \\
\circ & 10 \text { to } 20 \% \\
\circ & 20 \text { to } 30 \% \\
\circ & 30 \text { to } 40 \% \\
\circ & \text { More than } 40 \% \\
\circ & \text { I don't know }
\end{array}
$$

Survey regarding personal protective equipment (PPE) during the COVID-19 pandemic (continued)

9) In your opinion, has the readiness to put on PPE changed over the last 12 months?

$$
\begin{aligned}
& \text { No } \\
& \circ \quad \text { Yes, } \\
& \circ \quad \text { Yes, complete protective equipment is more important now } \\
& \text { Yes, complete protective equipment was more important at } \\
& \text { the beginning of the pandemic } \\
& \text { Yes, the readiness to put on protective equipment has } \\
& \text { developed very differently from one individual to another }
\end{aligned}
$$

10) Was any additional hygiene training offered in your EMS area of operation during the pandemic?

$$
\begin{array}{ll}
\circ & \text { Yes, one additional training } \\
\circ & \text { Yes, multiple/regular additional trainings }
\end{array}
$$

11) Is a SARS-CoV-2 test (rapid test) offered to staff on duty in your EMS area of operation?

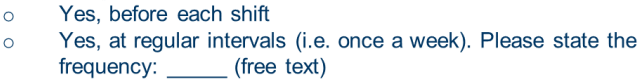

12) Are masks regularly worn at the duty stations of your EMS area of operation?

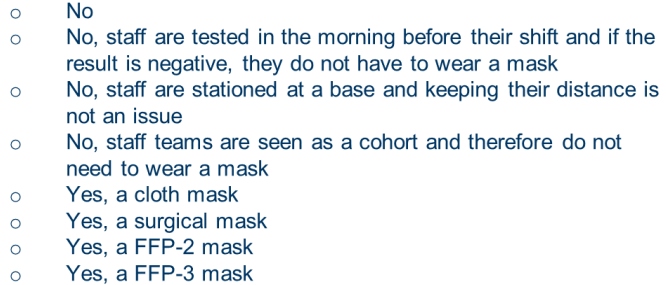

13) In your opinion, does more PPE need to be provided in your EMS area of operation?

$$
\text { - Yes }
$$$$
\text { No }
$$

14) How has the attitude toward SARS-CoV-2 changed in the last year in your EMS area of operation?

$$
\begin{aligned}
& \text { At the beginning of the pandemic, concern about becoming } \\
& \text { infected was } \\
& \begin{array}{llllll}
1 & 2 & 3 & 4 & 5 & 6
\end{array} \\
& \text { Very low very high } \\
& \text { - The concern about becoming infected is now } \\
& \begin{array}{llllll}
1 & 2 & 3 & 4 & 5 & 6
\end{array} \\
& \text { Very low very high }
\end{aligned}
$$

15) Have you been vaccinated against SARS-CoV-2? Yes (min. first vaccination received)

No, but I already have an appointment

No, but I am waiting for an appointment

$\mathrm{No}$ I do not want to be vaccinated

No, I might want to be vaccinated at a later stage 


\section{Survey Paramedical Staff and Emergency MDs}

\section{Demographische Daten}

1) Please state your gender.

- Male

- Diverse

2) Please state the first digit of your postcode.

\begin{tabular}{|l|l|l|l|l|}
\hline 0 & 1 & 2 & 3 & 4 \\
\hline 5 & 6 & 7 & 8 & 9 \\
\hline
\end{tabular}

3) To which of the following age categories do you belong?

$$
\begin{aligned}
& 18 \text { to } 29 \text { years } \\
& 30 \text { to } 39 \text { years } \\
& 40 \text { to } 49 \text { years }
\end{aligned}
$$$$
60 \text { years and older }
$$

Survey regarding personal protective equipment (PPE) during the COVID-19 pandemic

4) Which professional group in the EMS service do you belong to?

- Paramedical staff

- Emergency MDs

5) Which protective equipment do you put on when attending to a SARS-CoV-2 positive patient? (multiple answers possible)

$$
\text { - Gloves }
$$$$
\text { Protective Gown }
$$

$$
\text { Coveralls }
$$

Surgical Mask

FFP2-Mask

FFP3-Mask

FFP2- or FFP3-Mask (depending on availability)

Goggles

Face Shield

6) Which protective equipment do you put on when attending to a suspected SARS-CoV-2 patient? (multiple answers possible)

$$
\text { Gloves }
$$

Protective Gown

Coveralls

Surgical Mask

FFP2-Mask

FFP3-Mask

FFP2- or FFP3-Mask (depending on availability)

Goggles

Face Shield

7) Which protective equipment do you put on when attending to a patient who does not show any signs of SARS-CoV-2? (multiple answers possible)

Gloves
Protective Gown
Coveralls
Surgical Mask
FFP2-Mask
FFP3-Mask
FFP2- or FFP3-Mask (depending on availability)
Goggles
Face Shield

8) In your opinion, is there currently a sufficient amount of PPE available at your EMS rescue station/work location?

- Yes

9) Were there SARS-CoV-2 cases at your EMS rescue station/work location?

$$
\begin{array}{ll}
\circ & \text { Yes } \\
\circ & \text { No } \\
\circ & \text { I don't know/No answer }
\end{array}
$$

10) Do you have/have you had a SARS-CoV-2 infection?

$$
\begin{array}{ll}
\circ & \text { Yes } \\
\circ & \text { No } \\
\circ & \text { No answer }
\end{array}
$$

Survey regarding personal protective equipment (PPE) during the COVID-19 pandemic (continued)

11) Have you been quarantined due to an occupational SARS-CoV-2 contact?

$$
\begin{array}{ll}
\circ & \text { No } \\
\circ & \text { Yes, once } \\
\circ & \text { Yes, twice } \\
\circ & \text { Yes, more than twice }
\end{array}
$$

Condition: If answer is Yes $\rightarrow$ Question 11a visible

11a) Was the SARS-CoV-2 contact a patient or their relative (occupational contact)?

$$
\begin{array}{ll}
\circ & \text { Yes, every time } \\
\circ & \text { This varied from contact to contact } \\
\circ & \text { No }
\end{array}
$$

12) Has your attitude concerning putting on PPE changed over the last 12 months?

$$
\begin{aligned}
& \text { No } \\
& \text { Yes, complete protective equipment is more important to me } \\
& \text { now } \\
& \text { Yes, complete protective equipment was more important to me } \\
& \text { at the beginning of the pandemic }
\end{aligned}
$$

13) Would you have wanted additional hygiene training in the context of the pandemic?

Yes, I would have liked additional training

Yes, there were trainings, but I would have wished for more

No, there was enough training

No, I would not have wanted additional training

14) Do you think that at the beginning of the pandemic there was already enough protective equipment available for you and your colleagues?

$$
\text { Y Yes }
$$$$
\circ \quad \text { No }
$$

15) Do you take advantage of the offer to be tested for SARS-CoV-2 (rapid test) at the start of your shift?

- Yes, at the start of each shift.

- Yes, at regular intervals (e.g. once a week). Please indicate how often: (free text)

- No, there is such an offer, but I do not take advantage of it

- No, there is no such offer

16) Do you regularly wear a mask at your duty station?

0
0 No, we are tested in the morning before we go on duty and if No, we are tested in the morning before we go on duty
the result is negative, we do not have to wear a mask

No, we are located at a base and keeping our distance is not a problem

- No, our team is seen as a cohort and we therefore do not need to wear a mask

Yes, a cloth mask

Yes, a surgical mask

Yes, a FFP2 mask

Yes, a FFP3 mask

17) Do you think more personal protective equipment needs to be provided at the duty station?

$$
\text { - Yes }
$$

- No

18) How has your attitude towards SARS-CoV-2 changed over the last year:

$$
\begin{aligned}
& \circ \quad \text { My concern to get infected at the beginning of the pandemic } \\
& \begin{array}{lcllll} 
& \text { was } & & & & \\
& 2 & 3 & 4 & 5 & 6
\end{array} \\
& \begin{array}{cccccc}
1 & 2 & 3 & 4 & 5 & 6 \\
\text { Very low } & & & & \text { very high }
\end{array} \\
& \text { - My concern to get infected now is } \\
& \begin{array}{llllll}
1 & 2 & 3 & 4 & 5 & 6
\end{array} \\
& \text { Very low very high }
\end{aligned}
$$

19) Have you been vaccinated against SARS-CoV-2?

Yes (min. first vaccination already received)

No, but I already have an appointment

No, but I am waiting for an appointment

No, I do not want to be vaccinated

No, I would possibly like to be vaccinated at a later date 